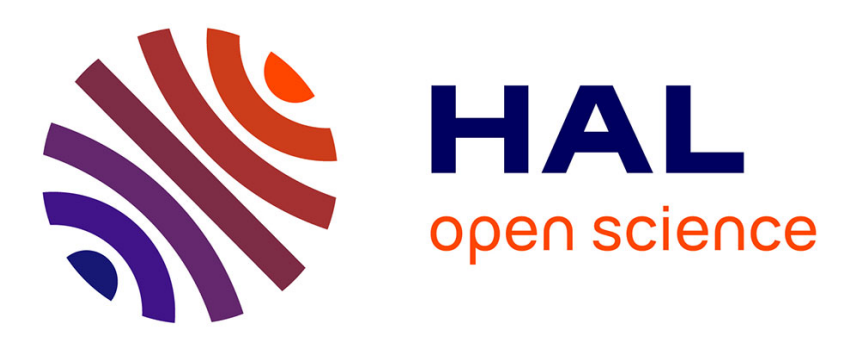

\title{
The Role of Error Type and Working Memory in Written Corrective Feedback Effectiveness on First-Language Self Error-Correction
}

Mohammad Nowbakht, Thierry Olive

\section{- To cite this version:}

Mohammad Nowbakht, Thierry Olive. The Role of Error Type and Working Memory in Written Corrective Feedback Effectiveness on First-Language Self Error-Correction. Written Communication, 2021, 38 (2), pp.278-310. 10.1177/0741088320986554 . hal-03351414

HAL Id: hal-03351414

https://hal.science/hal-03351414

Submitted on 13 Dec 2021

HAL is a multi-disciplinary open access archive for the deposit and dissemination of scientific research documents, whether they are published or not. The documents may come from teaching and research institutions in France or abroad, or from public or private research centers.
L'archive ouverte pluridisciplinaire HAL, est destinée au dépôt et à la diffusion de documents scientifiques de niveau recherche, publiés ou non, émanant des établissements d'enseignement et de recherche français ou étrangers, des laboratoires publics ou privés. 


\title{
The Role of Error Type and Working Memory in Written Corrective Feedback Effectiveness on First-language Self Error Correction
}

\author{
Mohammad Nowbakht \\ Department of English Language, Yazd University, Iran \\ (mohammad.nowbakht@yahoo.com)
}

Thierry Olive

National Centre for Scientific research (CNRS) and University of Poitiers, France

(thierry.olive@univ-poitiers.fr)

\begin{abstract}
PREPRINT of
Nowbakht, M., \& Olive T. (2021). The role of working memory on the effectiveness of direct and indirect written corrective feedback in detection and correction of spelling errors. Written Communication, 38(2), 278310. https://doi.org/10.1177/0741088320986554
\end{abstract}

\begin{abstract}
This study examined the role of error-type and working memory (WM) in the effectiveness of direct-metalinguistic and indirect written corrective feedback (WCF) on self error correction in first language (L1) writing. Fifty-one French first-year psychology students volunteered to participate in the experiment. They carried out an L1 error-correction task after receiving WCF on typographical, orthographic, grammatical, and semantic errors. Results indicated that error-type affected the efficacy of WCF. In both groups, typographical error-correction was performed better than the others; orthographic and grammatical error-correction were not different, but both were corrected more frequently than semantic errors. Between-group comparisons showed no difference between the two groups in correcting typographical, orthographic, and grammatical errors, while semantic error-correction was performed significantly better for the direct group. Results revealed that WM was not involved in correcting typographical, orthographic, and grammatical errors in both groups. It did, however, predicted semantic error-correction only in response to direct-metalinguistic WCF. In addition, the processing component of WM was predictive of semantic error-correction in the direct WCF group. These findings suggest that error-type mediates the effectiveness of WCF on written error-correction at the monitoring stage of writing, while WM does not associate with efficacy of all WCF types at this stage.
\end{abstract}

Keywords: working memory; error types; written corrective feedback, error-correction 
The Role of Error Type and Working Memory in Written Corrective Feedback Effectiveness on First-language Self Error Correction

Written corrective feedback (WCF) refers to reactive responses to errors in writing. WCF can target different aspects of language, such as grammar, vocabulary, and even pragmatic features both in first language (L1) and second language (L2) contexts. Within the context of the present study, WCF is used to draw writers' attention to various linguistic features (i.e., spelling, grammatical, and semantic errors) when performing an L1 proofreading (self-error correction) task.

Proofreading (i.e., the ability to detect and correct errors in texts) is one of the consequential components of learning to write (Chromik, 2002). It is a highly crucial topic in writing research both in L1 and L2 writing. Such a process can be assisted by the provision of feedback by teachers in school or academic contexts. Although feedback can generally be regarded as a learning tool, as examined in a plethora of research studies on oral or written corrective feedback within an SLA context, it can also be widely used as a noticing mechanism to draw writer's attention to their errors to improve the quality of the text they have written. As a matter of fact, students in different contexts (e.g., academic, languagelearning) frequently engage in this process. University teachers regularly provide feedback on their students' writings, expecting them to benefit from such feedback and improve the quality of what they have written; accordingly, it is valuable to know what factors and to what extent they influence the benefits students can garner from feedback while proofreading.

Proofreading requires both language-specific skills and higher-order cognitive processes, making it a cognitive and attention demanding activity (Hacker, Plumb, Butterfield, Quathamer, \& Heineken, 1994; Larigauderie, Guignouard, \& Olive, 2020; Pilotti, Chodorow, \& Thornton, 2004). While proofreading, writers scan the text to identify discrepancies between what is actually written and what is expected to be written, a process 
influenced by various factors such as familiarity with the content of the text (particularly for other-generated texts to be proofread) (Daneman \& Stainton, 1993, Levy, Di Persio, \& Hollingshead, 1992; Pilotti et al., 2004; Pilotti, Maxwell, \& Chodorow, 2006), characteristics of the task and individual differences in working memory (Juffs, 2004; Larigauderie et al, 2020; Leeser, 2007; Waters \& caplan, 1996), the type of error to be detected and corrected (Hacker, Plumb, Butterfeld, Quathamer, \& Heineken, 1994; Shafto, 2015), and the purpose of the error-correction task (i.e. whether the task is meaning-focused) (Beal, Bonitatibus, \& Garrod, 1990).

One of the factors which leads to differences in proofreading, as Hayes (1996) noted, is individuals' ability to detect errors, which was controlled in this study by providing the participants with WCF, informing them about the occurrence of errors and their exact location in the text. In fact, the present research is among the first studies to empirically examine the role of WCF in error-correction in an L1 context, and how it leads to the correction of different error types while proofreading.

The positive role of WCF in improving writing has been a contentious topic for two decades (for reviews, see Truscott, 1996, 2007, Truscott \& Hsu, 2008; Ferris, 1999). The advantageous effects of WCF on writing accuracy, and learning of specific linguistic features (within L2 contexts) are now admitted by studies conducted in this line of research (Ashwell, 2000; Bitchener, 2008, 2009a, 2009b; Bichener \& Knoch, 2008, 2010a, 2010b; Ene \& Upton, 2018; Ferris, 2006; Ferris \& Roberts, 2001; Ferris, Liu, Sinha, \& Senna, 2013; Foin \& Lange, 2007; Lopez, Van Steendam, \& Buyse, 2017;Van Beuningen, de Jong, \& Kuiken, 2008, 2012).

The relative effectiveness of different types of WCF on improving writing accuracy, text revision, as well as the acquisition of particular linguistic forms was another line of inquiry focused by research. WCF can be categorized into direct, indirect, and metalinguistic 
feedback, focused vs. unfocused feedback, and reformulation, that is, teachers' rewriting of students' texts (Ferris, 2010). Direct WCF is defined as a kind of feedback that provides the explicit correction of the erroneous form just above or near it, while indirect WCF signals the location of an error, for instance by means of underlining or circling to facilitate its correction but does not provide students with the correct form (Bitchener \& Ferris, 2012). Metalinguistic WCF is a subset of direct feedback, which provides grammatical rules and correct form examples, but does not provide any explicit correction. In (1) examples of the WCF types are provided:

(1) Direct: Indirect:

Metalinguistic: *All the children likes to play soccer.

(WCF: "When the subject is plural, we must use a plural verb.

Direct and indirect WCF have been compared in previous studies with different findings. Some of the earlier studies reported little or no difference between the two (Lalande, 1982; Semke, 1984; Robb, Ross, \& Shortreed, 1986), or found short-term effectiveness for indirect WCF (Truscott \& Hsu, 2008), whereas more recent studies provided evidence in favor of direct feedback (Van Beuningen et al., 2008, 2012, Bitchener \& Knoch, 2010b), arguing that direct WCF diminishes the confusion that students may experience while trying to understand the indirect feedback, provides them with correct linguistic input, and guides them in the process of modifying more complex linguistic errors, such as syntactic structures, semantic errors, and idiomatic language (Bitchener \& Ferris, 2012). Supporters of indirect feedback(Lalande,1982), on the other hand, contend that it can help students engage in active learning and problem solving, which in turn may contribute to becoming their own editors. 
Different forms of direct WCF (e.g., direct WCF with and without metalinguistic explanation) have also been compared (Bitchener, Young, \& Cameron., 2005; Bitchener, 2008; Bitchener \& Knoch, 2008, 2010a; Shintani \& Ellis, 2013). In addition, the effectiveness of WCF on short-term revision performance (Ashwell, 2000; Ferris, 2006; Sachs \& Polio, 2007; Truscott \& Hsu, 2008), and on long-term writing improvement (Chandler, 2003; Foin \& lange, 2007; Vytakinam, 2010) have been explored. These studies have yielded conflicting findings. Some of these relate to design and methodology (e.g., absence of a control group, the use of differing task types for study groups), while others relate to factors such as linguistic variation (i.e., incorporating a variety of linguistic features) and individual differences.

Accordingly, the validity of such findings may have been influenced by other factors or mediating variables which were not included in their study designs, such as the context in which the research was carried out, for instance, in SLA or composition classes (Bitchener \& Ferris, 2012), the immanent characteristics of the linguistic features used, and the individual differences factor such as proficiency level or memory (Ammar, 2008; Ellis, Loewen, \& Erlam, 2006).

\section{Factors Affecting WCF effectiveness}

In his framework for investigating corrective feedback, Ellis (2010) proposed three interacting variables that may interfere with the efficacy of corrective feedback, namely, individual differences, linguistic features, and contextual factors. Individual differences can incorporate cognitive (e.g., age, aptitude, memory, cognitive styles), affective (e.g. anxiety, personality, motivation) and social (e.g. attitudes, beliefs, gender, and preferences) facets (Pawlak, 2014).

Linguistic features pertain to the idea that corrective feedback may impact various linguistic forms differently. For example, students' readiness to perform the syntactic 
operation, the level of complexity of the linguistic form, the salience of the linguistic form and its communicative value (Goldschneider \& DeKeyser, 2001; Spada \& Lightbown, 2010), the influence of students' first language (White, 1991), and the dimensions of the linguistic feature such as form and meaning (Pawlak, 2014) may impact the production and revision of these linguistic forms. In other words, certain types of corrective feedback may be more effective for correcting one particular error but not for others. For instance, Lopez, van Steendam, Speelman, \& Buyse, (2018) indicated that certain types of grammatical errors may be more susceptible to a particular feedback type than other grammatical structures.

Contextual factors can also mediate the efficacy of corrective feedback. This factor, as Ellis (2010) noted, is associated with attributes of the overall educational context (e.g., first or second language contexts, foreign or second language classes, the type of curriculum used), and the minor features of the learning context, such as the activities performed within the classroom.

A small number of studies have thus far attempted to address the role of these variables in both oral and written corrective feedback efficacy. Goldstain (2006), for instance, showed that motivation, as an affective individual difference, is a significant determinant in WCF efficacy. Sheen (2007) provided evidence for the role of aptitude, a cognitive individual difference, in the utility of corrective feedback, especially metalinguistic WCF. Evidence attesting to the role of students' proficiency level in WCF comes from studies by Ferris and Roberts (2001), who indicate that higher proficiency leads to more successful self-editing, and Qi and Lapkin (2001) and Watanabe and Swain (2007) who provided evidence that proficiency level influences the quality of text revisions.

More pertinent to the present study, Li and Roshan (2019) indicated that working memory is associated with the effectiveness of direct and metalinguistic WCF on learning grammar although their study was conducted in an L2 context. Their findings revealed that 
working memory was a positive predictor of metalinguistic WCF without revision and direct WCF with revision. Framed in an aptitude-by-treatment approach, the study successfully showed that working memory has different effects on different WCF types with their various processing demands. Conspicuously, research on the impinging role of such factors in corrective feedback efficacy, particularly WCF, is scarce to date (Pawlak, 2014), suggesting a pressing need to embark on this line of research. There is also a dearth of research when it comes to the role of working memory in WCF effectiveness. This is somewhat surprising given the body of research that corroborates the significant role of working memory in human development and cognitive tasks, such as writing and all its stages (Engle, Kane, \& Tuholski, 1999; Hayes, 1996; Kellogg, 1996; Gathercole \& Alloway, 2008; Kellogg, Whiteford, Turner, Cahill, \& Martens, 2013; Olive, 2004).

\section{Link between Working Memory and WCF}

Exhaustively researched in cognitive psychology, Working Memory (WM) has been found to play a pivotal role in human cognitive activities. It is defined as the ability to maintain information in an active state, while simultaneously processing new incoming information (Conway, Jarrold, Kane, Miyake, \& Towse, 2007); thus, by definition, it incorporates the two components of information storage and processing (Baddeley, 2007).

Different models of WM, as well as the relationship between WM and high order cognitive activities have been discussed in a rich profusion of theoretical explanations and empirical experiments (Baddeley, 2000, 2007; Baddeley \& Hitch, 1974; Conway et al., 2007; Cowan, 2005; Jarrold \& Towse, 2006; Miyake, 2001). One of the most recognized conceptualizations of WM is the multicomponent model (Baddeley, 2000; Baddeley \& Hitch, 1974), which divides WM into four components: the central executive, the phonological loop, the visuo-spatial sketchpad, and the episodic buffer. The central executive is an attentional control mechanism responsible for directing the flow of information in the system (Baddeley, 
2003). The phonological loop deals with the storage and manipulation of verbal and acoustic information, whereas the visuo-spatial sketchpad is specialized for retention and processing of the visual and spatial information. Finally, the episodic buffer is a component that is in connection with the long-term memory, and has the function of integrating information received from other components into episodes (Baddeley, 2000).

Writing processes (i.e. planning, translation, execution, and monitoring) have been argued to be supported by WM and its components (Hayes, 1996; Kormos, 2012; Kellogg, 1996; Kellogg, Whiteford, Turner, Cahill, \& Mertens, 2013; McCutchen, 2000; Olive, 2004, 2012). For instance, in the translation process, as Kellogg et al. (2013) argue, writers may be required to keep the produced idea in their mind, which taps into the storage component of WM, while trying to transcribe the ideas and turn them into words, which itself involves complex cognitive processes of lexical items retrieval, syntactic encoding of clauses and sentences, and establishing cohesiveness throughout the text (Hayes \& Chenoweth, 2006; Kormos, 2012; Olive, 2012). Hence, it can be stated that writing processes are activated and coordinated in a cognitive space called working memory (Olive, 2014).

WM is also involved in the monitoring stage of writing (Kellogg, 1996; Kellogg et al. 2013). This stage involves reading and editing of the produced writing. Writers, in this stage, read their compositions again, and check it for any errors or mismatches between their intention and the actual created text (Kormos, 2012), which may result in text revision. The provision of WCF can be assumed to play an important role during the monitoring stage, which is itself influenced by the executive function and the phonological loop (Kellog, 2006; Kellog et al., 2013). As a result, it can be true to assert that individuals with differing WM may also show variation in the amount of benefit they can provide after receiving WCF during the monitoring stage of writing. 
The processes of noticing the error (error-detection) and error-correction are cognitively demanding (Roussey \& Piolat, 2008); hence, they are hypothesized to be highly affected and controlled by individual differences in WM. Upon receiving WCF, students or writers may store and process the new incoming information by drawing on their WM (i.e., they retrieve knowledge about a specific form, for which the WCF is provided, from their long-term memory, and keep it in an active state in working memory); while concurrently processing the new information received through feedback. The potential effect of WM in written feedback effectiveness may be even more conspicuous with regards to different types of feedback as well as different error types to be corrected.

Previous research has indeed focused on the effects of various factors on proofreading in L1. The type of error was found to be one of those significant factors: word-level errors (such as typographical and orthographic errors) are detected and corrected better than those that require a deeper processing of a larger portion of the text such as semantic errors (Levy, Di Persio, \& Hollingshead, 1992; Shafto, 2015). Another factor studied in proofreading research was the effect of familiarity with the text, which was found to improve the detection and correction of grammatical and semantic errors (Levy, 1983), and generally the speed and accuracy of processing the text while proofreading (Pilotti et al, 2004). WM was also found to be positively influential in this process. Studies have shown that higher spans of WM lead to better error-detection and correction performance; hence, proofreading is highly dependent on WM constraints (Kellog et al., 2013; Larigauderie et al, 1998, 2020; McCutchen, Francis \& Kerr, 1997; Piolat \& Medrad, 1998).

A previous study (Larigauderie, Gaonac'h, \& Lacroix, 1998) attempting to explore WM roles in the detection and correction of different error types (i.e., typographical, orthographic, syntactic, and semantic errors) while proofreading in a first-language context, has indicated that WM plays a crucial role in L1 proofreading: the central executive is 
effective in the detection of semantic, syntactic, and orthographic errors, but not in typographical errors. In addition, the phonological loop is effective in detecting errors above the word level, such as semantic errors.

In another study, Piolat, Roussey, Olive, and Amada (2004) investigated the effects of different error types and individual differences in WM on text revision efficiency and cognitive effort and temporal organization of the sub-processes of revision (i.e., reading to define problems, searching a solution, and transforming a text), evaluated by using the tripletask method (Olive, Kellogg, \& Piolat, 2001). Cognitive effort is defined as "the amount of resources required by a task" (Piolat et al., 2004, p. 22). The results of their study supported the role of error types and WM in revision efficiency, but not in cognitive effort and temporal organization of revision sub-processes. Different findings, however, were obtained in a more recent study in which no evidence was found supporting the role of WM in the processes of revision (Evans, Caplan, Ostrowski, Michaud, Guarino, \& Waters, 2015).

In a recent study, Larigauderie et al. (2020) investigated the role of WM (i.e., executive and non-executive components) in the detection and correction of phonological, orthographical, and grammatical errors. The non-executive component refers to verbal and visuospatial storage, while the executive component pertains to coordination between the verbal and visuospatial storage, retrieval from long-term memory, and effortful shifting. Results revealed that WM is involved in proofreading, and that the executive component of $\mathrm{WM}$ is more involved in the verbal domain, whereas the non-executive component is mainly involved in the visuospatial domain.

A review of the existing literature surprisingly reveals that, to date, little research has strived to delve into the role of WM in the effectiveness of WCF on revision and errorcorrection. Research is also scarce when it comes to the mediating role of WM in different types of WCF and students' error-correction performance. Given the theoretical link between 
WM and editing a text, as well as a dearth of studies exploring the role of mediating variables (e.g. linguistic factors, individual differences, etc.), the present study is designed to address the potential role of linguistic factors (i.e. error types: typographical, orthographic, grammatical, and semantic errors) as a mediating variable in error-correction in response to two types of WCF (i.e. direct-metalinguistic WCF and indirect error location WCF). Another objective of the study concerns the potential role of WM in the effectiveness of the two types of WCF on participants' error-correction. The study was conducted within an L1 context, and the motivation behind it was to examine how WCF, which is a useful tool to draw writers' attention to errors, is influenced both by WM and by linguistic factor (operationalized by using four different types of errors for correction) when individuals are performing an L1 selferror correction task. While it is true that feedback has mostly pedagogical aims, helping learners to notice the gaps in their interlanguage system, it is a widely used means of drawing students' attention to their output (written and oral) and can be a powerful tool within firstlanguage contexts, particularly in academic settings where students are required to do plenty of writings.

This study attempts to answer the following research questions:

1. To what extent do error types affect the effectiveness of direct-metalinguistic and indirect WCF on self-error correction?

2. To what extent does WM and its separate components (i.e. storage and processing) affect the effectiveness of direct-metalinguistic and indirect WCF on self-error correction?

To address the first question, the participants engaged in an L1 error-correction task. The task involved reading a text containing the four types of errors and correcting the errors based on the WCF provided. WCF effectiveness is operationalized by the number of successful error-corrections in response to a particular type of WCF. Subsequently, the 
differences between the two groups in WCF effectiveness on correcting the four error types were examined. For the second question, the association between participants' WM and errorcorrection in response to WCF was checked.

The reason for selecting direct-metalinguistic and indirect WCF in our study was that these two types of feedback may draw differently on WM due to their different levels of explicitness. Direct-metalinguistic WCF provides information regarding the types of error and a correct example of it; hence, it is more explicit than indirect feedback, and may be less demanding for WM. In other words, when receiving metalinguistic WCF, participants do not have to retrieve the related knowledge from their long-term memory and find the types of error they made; rather, they only engage in correcting the error according to the feedback. In indirect WCF, on the other hand, only the location of the error is highlighted, and no other information is provided. Participants must figure out the types of error (i.e., orthographic, grammatical, etc.), retrieve the relevant information, and engage in processing the error to correct it; as a result, this process may be more demanding for WM. That being the case, it can be stated that the two types of WCF may be influenced differently by WM. These two feedback types are also common error-treatment techniques used by teachers in academic contexts, and due this prevalence, it is worthwhile to investigate their effects on the correction of different error types, as well as the mediating role of WM in this process.

\section{Method}

\section{Participants and Setting}

The participants were 51 male and female first-year psychology students in a University in France. They all volunteered to take part in the study by registering their names in a course-credit platform, designed to recruit participants for experiments. They were all French native university students who mastered their native language and did not experience 
language difficulties. Their ages ranged from 18 to $23(M=19.60)$. The participants were randomly assigned to two WCF groups: a direct-metalinguistic group $(\mathrm{N}=26)$ and an indirect group $(\mathrm{N}=25)$. All volunteers signed an informed consent to participate in the study. Prior to the experiment, they were all screened for the intervening influence of any medical issues, any hearing or sensory complications or medicine that could possibly influence their level of concentration or attention. This experiment adhered to the ethical guidelines in accordance with the Declaration of Helsinki.

\section{Materials and Tasks}

Working memory test. A first-language Operation Span Task (OSPAN) was taken collectively to measure the participants' WM. OSPAN is an extensively used task in WM studies to measure complex working memory (Conway, Kane, \& Engle, 2003; Rosen \& Engle, 1998; Unsworth \& Engle, 2007). It is considered a less language-dependent task (Turner \& Engle, 1989) compared with other WM tasks, such as the sentence-span task (Daneman \& Carpenter, 1980). The OSPAN used in this study was adopted from Unsworth, Heitz, Schrock, and Engle (2005). During the test, the participants were required to maintain French alphabet letters (as recall items) in their memory for several seconds, which taps into the storage component of WM, while concurrently solving a simple mathematical operation, which measures the processing component of WM. The task was presented to participants in Microsoft PowerPoint using a computer and a video projector, and included a total number of 81 mathematical questions (e.g., $3+(4 \times 2)=$ ?), distributed in sets of $2,3,4,5,6$, and 7 . A set of 2 , for instance, comprised two mathematical questions for the participants to answer, a set of 3 contained 3 questions and so forth. Each mathematical question contained only two operations (i.e., an addition, a subtraction, or a multiplication). Accordingly, all questions resembled the one displayed above with only two operations within each. There were 3 series for each set size, meaning that sets were repeated three times in the test. 
All participants received the same sets and in same order. The order of the sets was similar for all participants because the test was administered collectively. During the administration of the task, the participants were asked to look at a mathematical question on the first PowerPoint slide shown by a video projector for $3000 \mathrm{~ms}$, followed by a number on another slide (displayed for $3000 \mathrm{~ms}$ ) as a possible answer to the mathematical question. The participants were supposed to decide in $3000 \mathrm{~ms}$ if the number was a correct answer to the question, and subsequently mark a 'Correct' or 'Incorrect' answer on their answer sheets. Following this slide, a French consonant as the recall item appeared for $1000 \mathrm{~ms}$, which the participants had to keep in their memory. The recall-item slide was automatically followed by a new mathematical question, repeating all the above procedure depending on the size of the set. For example, in a set size of 2, only 2 mathematical questions with their possible answers and two recall items were shown. At the end of each set, a recall cue word (i.e., "Rappel" which means "recall" in French) was displayed, asking participants to write the recall items (i.e., the consonants) in the order of presentation on their answer sheet. The time allotted for writing the recall items varied depending on the size of the set: for instance, for the set size of 2, the time given was $4000 \mathrm{~ms}$; for the set size of 3, $6000 \mathrm{~ms}$, set size of 4, $8000 \mathrm{~ms}$, set size of 5, $10000 \mathrm{~ms}$; set size of 6, $12000 \mathrm{~ms}$, and for the set size of 7, it was $14000 \mathrm{~ms}$ (for an example of a set size of 2, see Appendix A).

To score the task, the partial-credit load scoring technique (Conway, Kane, Bunting, Hambrick, Wilhelm, \& Engle, 2005) was used, in which 1 point was given to each correctly recalled consonant in its correct serial position only if the processing item (i.e., the mathematical equation corresponding to that consonant) was correctly solved. Therefore, the possible score one could obtain ranged between 0 and 81 . The closer participants' score to 81 , the higher WM span they possess. 
Error types. Four types of error were chosen for the purpose of WCF provision and error-correction, namely, typographical, orthographic, grammatical, and semantic errors. A total number of 24 error cases were randomly inserted in the texts, with 6 cases for each type of error. The errors were inserted in the text by a French native university professor, who has a complete mastery over French. They were meticulously selected and examined before being inserted in the text (i.e., semantic errors were truly semantic in nature, and grammatical errors were indeed grammatically ill-formed).

We included different sub-types of errors for each error category to ascertain students were not exposed to only one form of each error type. Because we did not find studies providing evidence of systematic performances with the different sub-types of semantic error we used in this study, we did not make any hypothesis on the subtype of semantic errors. In addition, using these different forms allowed generalization of the findings.

Typographical errors (also called typos) are misspelled words that if pronounced, would cause an incorrect phonological sequence (Larigauderie et al., 1998; Larigauderie, et al., 2020). Four types of typos were inserted in the text: Letter migrations (i.e., the positions of two adjacent letters in a word change), letter substitution (i.e. a letter is substituted with a wrong letter causing a wrong pronunciation), letter omission (i.e. a letter is omitted from a word), and letter commission (i.e. an extra letter is inserted in a word). Orthographic errors are misspelled words, whose phonological sequence remains unaffected by the error (e.g., relevent instead of relevant). Grammatical errors had different classes within our study. This error included violation of subject-verb agreement, wrong verb conjugation, and syntactically wrong use of pronouns.

Finally, semantic errors included errors whose presence would affect sentence meaning; therefore, the participants required comprehension of a larger portion of the text to correct them. Different types of semantic errors were inserted in the text including omission 
of verbs, adjectives, adverbs or relative pronouns (e.g. I really enjoy watching horror movies because one never what is going to happen. [missing verb: one never knows]); the use of redundant words or pleonasms (Matthews, 2007) which do not jeopardize sentence meaning and add nothing extra to the sentence (e.g., He himself wrote his autobiography of his own life. Note: An autobiography, by definition, must have been written by him and nobody else, and it is always about ones' life); and incorrect usage of a word which is not coherent with the sentence (e.g., these animals are awake during the night; however, during the night they go to their shelters).

The reason for the selection of these error categories is to ascertain participants use different levels of cognitive effort to correct them in order to determine how WCF assists this process and what effects individuals' WM spans have on it. The correction of these errors requires different levels of cognitive effort and results from different cognitive operations (i.e., graphomotor for typographical errors, spelling knowledge for orthographical). Previous research also backs the idea that different types of errors pose different degrees of difficulties for native speakers. For instance, Larigauderie et al. (2020) clearly indicated that grammatical errors are harder for French native speakers to detect than lexical errors. In other studies (e.g., Larigauderie et al, 1998; Roussey \& Piolat, 2008), semantic errors required more effort for reads to revise.

Different components of WM may thus have different associations with the correction of each type of error. For instance, their detection and correction differently engage the nonexecutive and executive components of working memory, as showed by Larigauderie et al. (2020). Additionally, research has indicated that the central executive is effective in the correction of spelling, syntactic and semantic errors, and the phonological loop has associations with the correction of semantic errors, which are above the word level (Larigauderie, et al., 1998). That being the case, we can also expect that the correction of such 
error types be differentially affected depending on individual differences in WM. In addition, error type itself, with differing difficulty levels in their detection and correction, may act as a mediating variable in the effectiveness of different WCF types on error-correction.

Texts for error-correction. A standard uniform text was extracted from the French translation of a novel by Coben (1998). The text was 303 words in length (See Appendix B). The four types of errors were randomly inserted throughout the text, with 6 cases for each error type. The text was selected, and errors were inserted in the text by a Native French university professor who had a very high competence in French. Different classes of each error type (i.e. subtypes) were also used in the study to counterbalance the type of error. In other words, we did not want participants to correct only one form of each error type (e.g., semantic errors); therefore, we used sub-types for each error type to allow better generalizations of our findings. Previous research (Lopez et al., 2018) has indicated that some grammatical structures are more amenable to direct WCF than others. Although conducted within an SLA context, the study by Lopez et al. (2018) makes us heedful of this fact even in L1 contexts, and clearly suggests that different grammatical errors should be included in the study design. As a result, the text or the errors were not too difficult for native students. Two versions of this text were made for the two groups involved in the study. For the direct WCF group, direct-metalinguistic WCF was provided in the text by underlining the error and giving metalinguistic information regarding the type of error. For the indirect WCF group, errors were just underlined with no metalinguistic explanation. The participants were required to read the text and correct the errors according to the feedback provided. This task was used to investigate their ability to correct errors in response to WCF as mediated by WM and error types. To ensure that the participants would read the text to comprehend it, rather than to read individual words to correct errors, some comprehension questions followed the text, the answering of which required understanding of the text. 
Feedback types. Two forms of WCF were provided while the participants were performing the proofreading task, direct-metalinguistic and indirect WCF. Direct feedback usually necessitates providing the correct form (Stefanou \& Révész, 2015; Storch \& Wigglesworth, 2010), while indirect WCF commonly concerns corrections that let learners diagnose and correct the errors themselves (Ferris et al., 2013). These two definitions are straightforward; however, when it comes to defining WCF types that lie in between the two ends of this continuum, such as metalinguistic WCF, inconsistencies in definitions can be seen. Whereas some researchers classify metalinguistic WCF as direct (Bitchener \& Ferris, 2012), some others (Guénette, 2012) argue that it is closer to an indirect form of feedback.

In the direct-metalinguistic condition in this study, the participants were provided with the location of the error though underlining as well as information regarding the type of the error made (i.e., a typo, a grammatical error, etc.). They were required to provide the corrections near the error considering the metalinguistic explanation given. On the other hand, in the indirect condition, the participants were only notified of the existence of an error through underlining with no metalinguistic information. Like the members of the direct group, they were required to provide the corrections near the errors; however, they did not have any information regarding the type of error they were correcting.

\section{Procedure and Data Analysis}

We collected the data in one session of 60 minutes. First, we provided the participants with the necessary instructions regarding the procedure of the study to ascertain they knew what they were going to do and asked them to sign an informed consent. Then, we administered the OSPAN collectively using a video projector, which took 15 minutes. Subsequently, the participants engaged in the error-correction process when reading the text on which direct-metalinguistic WCF for the direct group, and indirect WCF for the indirect group, was provided. We gave them sufficient information regarding the four types of errors 
they were supposed to correct in response to WCF. The participants were also required to write down the time they spent on the text from a chronometer displayed by a video projector in a particular space provided just below the text. The purpose for asking them to write the spent time was to examine whether time acted as a covariate in their ability to correct errors.

In error-correction experiments, it is highly important that participants be motivated enough to show their best ability in error-correction and take the experiment seriously. We did our best to ensure treatment fidelity in the study. First, the data was collected in a university in France where participants were recruited officially using a course credit system which allows them to claim extra scores after participating in an experiment successfully. Since all the experiments are carried out using this system, it provides a strong incentive and external motivation for students to take part in different laboratory experiments to gain extra scores or credits for their final exams. Although the participants were psychology students who were quite familiar with WM tests and such experiments, a French University professor instructed them carefully on what exactly they were expected to do, both in the error-correction task and OSPAN. In addition, upon collecting the data, we informed the participants that random responses would be terminated from the experiment, and as a result the responsible person would not be able to claim scores; therefore, we constantly watched participants' behavior while they were sitting in the class and doing the tasks to identify the violating cases. Finally, when scoring the OSPAN, a cut-score of $65 \%$ for mathematical questions was applied. This means that those students whose scores were below $65 \%$ of the processing WM (i.e., mathematical questions) were excluded from the study (3 students were ultimately removed). As a result, we can be certain that those remaining students have truly attended to the OSPAN. 


\section{Results}

\section{Error Types and the Effectiveness of WCF on Self Error-correction}

To investigate the relative effectiveness of direct-metalinguistic and indirect WCF on the correction of errors, a $2 \times 4$ mixed ANCOVA was used with error types as the withinsubject factor, and WCF types as the between-subject factor whilst controlling for the reading time. Results indicated a significant main effect of error types, $F(3,135)=18.44, p<.001$, Partial $\eta^{2}=.291$, and an interaction between error types and WCF groups, $F(3,135)=3.91, p$ $<.05$, Partial $\eta^{2}=.017$. Additionally, the interaction between error type and the reading time, as a covariate, was not significant, $F(3,135)=1.07, p=.366$. Table 1 displays the descriptive statistics for groups' performance in error-correction.

Table 1

Descriptive Statistics for Error Correction

$$
\text { Direct-Metalinguistic WCF }(N=24) \quad \text { Indirect } W C F(N=25)
$$

\begin{tabular}{lcccc}
\cline { 2 - 4 } Error & Mean & SD & Mean & SD \\
\hline Typo & 5.625 & 0.575 & 5.760 & 0.435 \\
Orthographic & 4.666 & 0.564 & 4.360 & 0.700 \\
Grammatical & 4.750 & 1.188 & 4.640 & 1.350 \\
Semantic & 1.125 & 1.454 & 0.200 & 0.500
\end{tabular}

Note: $\mathrm{SD}=$ standard deviation

Since an interaction effect was found between WCF groups and error types, simple main effects for group and for error types were run separately using a general linear model (GLM). Regarding the simple main effects of error types, results indicated that the correction of errors was significantly different in the direct-metalinguistic group, $F(3,69)=113.805, p<$ .001 , Partial $\eta^{2}=.832$, and in the indirect group, $F(3,72)=290.007, p<.001$, Partial $\eta^{2}=$ 924. Pairwise comparisons revealed that in both groups correction of typographical errors 
was significantly better than that of orthographic errors $(p<.001$ for both comparisons), grammatical errors ( $p<.05$ for both comparisons), and semantic errors $(p<.05$ for both comparisons) suggesting that typographical errors were the easiest for the participants to correct than the other error types. In addition, orthographic and grammatical error-correction were not statistically different ( $p>.05$ for both comparisons) in either of the groups; however, the correction of both error types was significantly better than semantic errors in both groups ( $p<.001$ for all comparisons), which means that semantic errors were the most challenging for the participants to correct.

As with the simple main effects of WCF groups, results of univariate GLM for each type of error indicate that the correction of typographical $(p=.358)$, orthographic $(p=.099)$ and grammatical errors $(p=.764)$ was not different between direct-metalinguistic and indirect groups; however, semantic error-correction was significantly better in the directmetalinguistic group than the indirect group, $F(1,47)=9.015, p<.05$, Partial $\eta^{2}=.161$, suggesting that direct-metalinguistic WCF led to better correction of semantic errors.

The correlations between the error types within each WCF condition was also measured. Results of the Pearson correlation in the direct group indicated no significant correlation between any of the four error types ( $p>.05$ for all correlations); however, in the indirect group, positive correlations were found between the typographical and orthographic error-correction $(r=.56, p=.003)$, typographical and grammatical error-correction $(r=.48, p$ $=.01)$, and orthographic and grammatical error-correction $(r=.62, p=.001)$.

\section{WM and the Effectiveness of WCF on Self Error-correction}

In order to examine the associations between WM and the participants' errorcorrection performances in response to the two types of WCF, different linear regression analyses were run, with WM scores as the predictor, and error-correction scores as the outcome variable. Results of the regression analyses revealed that WM was not predictive of 
the correction of typographical errors $(p=.415$ for the metalinguistic group, and $p=.390$ for the indirect group), orthographic errors ( $p=.283$ for metalinguistic group, and $p=.362$ for the indirect group), and grammatical errors ( $p=.542$ for the metalinguistic group, and $p=$ .526 for the indirect group) in any of the WCF groups. WM, however, significantly predicted semantic error-correction in the direct-metalinguistic group, $F(1,20)=5.586, p<.05$, accounting for $21.8 \%$ of variation in semantic error-correction scores (adjusted R2 $=17.9 \%$ ), while it failed to predict semantic error-correction in the indirect group $(p=.974)$.

To examine the relationship between the separate components of WM (i.e., WM storage and WM processing) and the effectiveness of the two types of WCF on errorcorrection, separated multiple regression analyses were run with the WM storage and processing as the predictors and error-correction scores as the outcome variable. The results revealed that, similar to WM, none of its components predicted variation in typographical, orthographic, and grammatical error-correction in either of the two groups ( $p>.05$ for all comparisons). Of the two WM components, WM processing, however, significantly predicted variation in semantic error-correction in the direct group, $F(2,19)=4.109, p<.05$, Beta $=$ .463 , while none of the two components were predictive of semantic error-correction in the indirect group $(p=.186)$.

\section{Summary of Results}

The results of the study indicated that error types (as a mediating variable) influence the efficacy of direct-metalinguistic and indirect WCF in error-correction. In both groups, the correction of typographical errors was done significantly better than the other error types, and similar results were found for the correction of orthographic and grammatical errors, while both were corrected better than semantic errors. Moreover, typographical, orthographic, and grammatical error-correction were not significantly different between the two groups; 
however, direct-metalinguistic WCF led to better semantic error-correction than indirect WCF.

As with the role of WM in the relative effectiveness of WCF on error-correction, we found that WM does not predict WCF effectiveness on ability to correct typographical, orthographic, and grammatical errors in undergraduate students. However, it successfully predicted the efficacy of the direct-metalinguistic group in semantic error-correction, while no association between WM and indirect WCF efficacy was found for the correction of semantic errors. The processing component of WM was also predictive of variation in semantic errorcorrection in response to the direct-metalinguistic group.

\section{Discussion}

The objectives of this study were to examine the impact of two mediating variables, (i.e. error type as a linguistic factor, and working memory (WM) as a cognitive factor) in the effectiveness of Written Corrective Feedback (WCF) on written self error correction. The role of such variables that may mediate the effectiveness of WCF on error-correction and learning linguistic forms has been minimally investigated in previous studies. Among such variables, the impact of students' motivation (Goldstain, 2006), aptitude (Sheen, 2007), language proficiency (Ferris \& Roberts, 2001; Qi \& Lapkin, 2001), and WM (Li \& Roshan, 2019) on WCF effectiveness was examined, all of which attested to the significant role these factors play in error-correction, text revision and learning in response to WCF.

The first objective of the study was to examine the role of linguistic factors in the effectiveness of WCF on error-correction. Linguistic factor was operationalized by four types of errors. Each error type also contained different sub-types to ensure that participants were not exposed to only one form of that error, facilitating the generalizations of our findings. The findings revealed that error types affected error-correction performances in response to direct-metalinguistic WCF and indirect WCF, and participants' performances were different 
according to the WCF as well. Comparisons between error types revealed that French native students who were at the tertiary level corrected the four types of errors differently, with the typographical errors being the more frequently corrected errors, and semantic errors being the less corrected errors. Such a finding is in line with that of previous studies suggesting that typographical errors were the least difficult and corrected with the highest frequency, and semantic errors the most effortful and corrected with the lowest frequency (Larigauderie et al, 1998, 2020; Roussey \& Piolat, 2008). Correction of orthographic and grammatical errors was not different from one another, while semantic errors were corrected with the least frequency in both groups compared with other error types.

Results of the between-group comparison of the direct-metalinguistic and indirect WCF in terms of error-correction also revealed that the correction of typographical, orthographic and grammatical errors did not differ across the two groups, while the correction of semantic errors was found to be significantly better for the direct-metalinguistic WCF group than the indirect WCF. In other words, semantic errors, previously shown to be more effortful for students to detect and correct, differentiated between the two WCF in their effectiveness on error-correction. Overall, not only does error type affect WCF effectiveness in general, but it also discriminates between the two WCF.

Differences in the effectiveness of WCF caused by error types can be justified considering the differing levels of error complexity as well as the demands of the WCF types in error-correction. Errors that required processing at the word level (e.g., typographical and orthographic errors) were easier to correct than errors (e.g. semantic errors) that needed processing beyond the word level (Larigauderie, et al., 1998). Semantic errors required global processing of a sentence (Larigauderie, et al., 1998) in which the participants need to read the sentences containing the errors to fully understand them; hence the processing moves beyond single word understanding. Larigauderie et al. (2020) have also found a high intervention of 
executive WM in semantic errors in contrast to spelling ones. Based on these findings, it can be argued that semantic errors require effortful deep processing; as such, writers in the present study may have processed the text with a surface reading, as for detecting spelling errors. On the contrary, typographical and orthographic error-correction did not involve sentence reading and comprehension but required processing of single words with few cognitive resources needed (Larigauderie, et al., 1998; Piolat, et al., 2004).

Additionally, semantic error correction, arguably, requires more problem-solving skills and more decisions to be made on the part of the students. It demands processing the sentence at the global level. In contrast, lexical and grammatical error correction is more welldefined; it has only one solution, one correction (e.g., the verb does not agree in number with the subject so it can be edited in only one way). But semantic errors may be more open-ended, may be subject to more flexible interpretations, making its correction less decisive and more effortful than other error types. These may be the reasons why semantic errors were not corrected as frequently as the other error types.

Other possible alternative explanations also need to be considered for the poor performance of native speakers on semantic errors. First, although very clear explanations were provided by a native university professor at the time of data collection, we still cannot really be certain what had happened in participants' minds when completing the task. For instance, they may have not fully understood the instructions and the task, or they could have been under the false impression that the task was timed (because they were supposed to write the amount of time they spent for the task) and so felt a need to finish as quickly as possible. Alternatively, fixated on lexical and grammatical errors, participants may have decided not to correct such errors (e.g., pleonasms) simply because they assumed this was not what they were supposed to correct. Finally, they may have interpreted the sentences with semantic 
errors in a different way than expected, for instance by judging semantic errors as accurate and letting them uncorrected.

As with the WCF groups, those who received direct-metalinguistic WCF performed significantly better in correcting semantic errors than the indirect WCF group. This finding demonstrates that direct-metalinguistic WCF may have depleted the cognitive effort required to correct semantic errors on account of its more explicit nature as compared with indirect WCF. Such a depletion culminated in a more efficient performance of those who were subjected to direct-metalinguistic WCF. Direct-metalinguistic WCF demands that individuals engage in error-correction according to the type of error and in some cases the correct examples. This can remove the burden of identifying the error type and diminish the intricacy with which they must grapple, which results in making less cognitive effort to correct the errors. Indirect WCF, on the other hand, is less explicit because individuals need to identify the type of error and partake in the error-correction process that can be influenced by their previous linguistic knowledge. The less explicit nature of indirect WCF, in this study, may have increased the cognitive effort entailed in correcting beyond-the-word-level semantic errors, ergo the poor performance of this group in semantic error-correction.

If the higher explicitness of direct-metalinguistic WCF can reduce the difficulty with error-correction, as reasoned above, one may expect to observe better performance for this group in correcting all four error types as compared with the indirect group, which was not what we found in this study. In fact, it is hard to argue that the detection of orthographic, typographical, and grammatical errors poses similar degrees of challenge for native speakers and involve cognitive operations that could be considered equivalent in terms of processing demands. In our view, the fact that we found that these three error types were corrected similarly does not support univocally the idea of a similar level of difficulty. We argue, rather, that this is mainly due to the presence of feedback (irrespective of its type) that may have 
facilitated error correction, which resulted in similar error-correction performances across the two groups, particularly for word-level errors (typographical and orthographic) and errors requiring local processing (grammatical errors).

But when it comes to semantic errors, more readings were required to fully understand the nature of the error and to correct it, which justifies its low correction performance. As described in the error categories section, the semantic errors used in the study were of different classes or sub-types ranging from semantic anomalies such as the use of pleonasms, which do not impede sentence comprehension and do not add anything extra to the sentence, to other forms of semantic errors such as omissions and incorrect usage of words, which render sentence meaning incoherent. Therefore, it cannot be concluded that only difficult semantic errors used in the study lead to students' poor performance in their correction, which, in turn, would allow better generalizations of the findings. It needs to be born in mind that the different sub-types of semantic errors were not compared in terms of students' ability to correct them, and that the overall semantic error-correction was examined. A reason why we did not compare semantic error subtypes was that we were not certain if they posed differing cognitive demands to students. We actually found no studies corroborating that different semantic error types can be differentially challenging for students. Hence, there was no reason to make comparisons between them.

It can be stated that indirect WCF, unlike direct-metalinguistic WCF, may not have been sufficient for facilitating the correction of such errors. In other words, participants may simply have not noticed what error they were dealing with due to lack of information about the error, while those who received direct-metalinguistic feedback were notified of the error type, which could have reduced their difficulty to correct the error. This justification can be supported by the fact that the majority of the semantic errors in the indirect WCF, unlike the direct-metalinguistic group, were left uncorrected. This suggests that the members of the 
indirect group may not have read the sentences for meaning and their processing was mostly kept at the word level. The correlation results in each WCF condition also revealed another interesting point about feedback effects on error-correction. While no correlation was found between the error types in the direct group, in the indirect condition, typographical, orthographic, and grammatical errors were all positively correlated with each other. This finding can be justified in light of the effect of indirect WCF on error-correction in that students are required to detect the type of error themselves and then engage in its correction. Participants in this group did not rely on any metalinguistic explanations, like those given to the direct group. Since they relied on their own linguistic knowledge to identify the type of errors and correct them, those who were more successful in correcting one type of error in the indirect condition, performed as successfully in correcting the other two types. Therefore, more corrections for typographical errors meant more corrections for orthographic and grammatical errors as well. In summary, the four different types of errors can be differentially challenging even for native speakers; however, feedback may have caused similar errorcorrection performance of these errors for native students.

The second objective of the study was to investigate the association between WM and the effectiveness of WCF on the correction of the four types of errors. The findings revealed that composite WM (i.e., storage WM plus processing WM) was predictive of the effectiveness of direct-metalinguistic WCF for semantic error-correction only, and it failed to predict the efficacy of indirect WCF in the correction of any error types. This means that WM plays a role in the effectiveness of direct-metalinguistic WCF but not indirect WCF. Results pertaining to the role of individual components of the WM (i.e., processing and storage WM) also revealed that the processing component was associated with semantic error-correction in the direct-metalinguistic WCF condition only. The storage component, however, did not predict the efficacy of WCF for any error types. 
The relationship between WM and WCF can be justified in light of the noticing mechanism underlying each type of feedback and the cognitive effort different WCF types place on students. The construct of noticing, as argued by Robinson (1995) is a detection process co-existing with awareness and rehearsal in short-term memory, which can be affected by constraints in WM. Illustrated in this sense, noticing can be a felicitous framing for direct-metalinguistic WCF as it was provided for the purpose of this research. Upon receiving the direct-metalinguistic feedback, the participants became aware of the presence of an error as well as its type, which can contribute to the rehearsal in short-term memory. The demand of the direct-metalinguistic WCF for processing the sentences containing semantic errors and comprehending them thoroughly may have increased participants' dependency on WM, thus fueling the association between WM and direct-metalinguistic WCF effectiveness on error-correction.

In contrast, those who received indirect WCF were only informed about the occurrence of the errors along with their locations; consequently, the identification of the error type and the finding of its pertinent rule in memory were handed over to the participants. This may have caused the participants in the indirect group not to be able to correct semantic errors simply because either they did not know they were semantic in nature or the feedback itself was not adequate to inform participants of the existence of such errors. Another alternative explanation as to why little association was found between WM and indirect WCF effects on correcting semantic errors may be that the type of feedback increased the cognitive effort required to correct the error. Such high cognitive effort could have led participants to entirely avoid correcting semantic errors.

However, as the findings display, the two feedback types had similar effects on typographical, orthographic, and grammatical error-correction, and WM was not associated with WCF effectiveness for the correction of such errors. A possible explanation of this 
finding, as argued above, may be that the presence of WCF, in general, facilitated the correction of word-level errors and local errors, fading the complexity differences among the three types of errors.

To sum up, those who received indirect WCF did not receive any information about the types of errors. The provision of WCF acted as a facilitator while performing the errorcorrections; hence, correcting typographical, orthographic, and grammatical errors was not a daunting task for them although no information was given to them regarding the type or nature of the error. This can explain the similar performances of both groups for the correction of these errors. In contrast, in the case of semantic error-correction, which requires a global processing of the text, participants in the indirect group left the errors uncorrected in many cases upon finding no misspelled or grammatical error. The justification of this finding is twofold: participants may have not been unfamiliar with the error type, and/or the cognitive effort needed to cope with such error in response to indirect feedback was too high, which resulted in a total abandonment of the error. This means that in most of the cases, when participants in the indirect group could not find any spelling or grammatical errors upon reading the semantic errors, they would leave the error unchanged and move to the next error for correction. A ramification of this behavior (i.e., leaving many of the errors uncorrected) may be that little association was observed between WM and correction in response to indirect WCF presumably because few corrections were carried out to show any predictive role for WM. It can also be alternatively surmised that processing at the word level could have been involved for correcting semantic errors, reducing the cognitive effort as compared with the direct-metalinguistic situation. Participants who received direct-metalinguistic WCF simply knew what type of error they were supposed to correct, which culminated in reading the sentences for meaning rather than form, better showing the amount of processing and cognitive effort required to correct such errors, hence strengthening their dependence on WM. 
This can also explain why the processing component of WM was predictive of directmetalinguistic WCF effectiveness only on correcting semantic errors. It can also be taken as a proof that performances in the direct-metalinguistic group were more dependent on their cognitive effort and processing as compared compared with the indirect group.

\section{Limitations}

The text used in this study was a standard uniform extract of a novel. Although the text was selected carefully and the errors were checked meticulously by a French university professor, it was still an other-generated text which is not very common in feedback studies. Student-generated writings could not be used in this study because we wanted to embed particular error types, with a few classifications for each error type in the text. Nevertheless, the use of a text not written by participants is the only solution that allows better error manipulation. When texts are written by participants, the experimenter must hope and wait for occurrences of the errors they are looking to examine. This is even more important for L1 studies, and for undergraduate students who are expected to have a high level of language proficiency.

Another limitation of the study pertains to the use of native speakers to investigate the comparative effects of WCF types on error-correction. The distinctions between WCF types as well as the correction of different error types could have been more conspicuous if L2 learners had been used, or the text had been written by the students themselves. However, the focus of the study was error type and WCF effects on proofreading a text rather than learning particular grammar forms as is common in L2 studies. Corrective feedback is a widely used technique to help students proofread and increase the quality of the writings on which WCF is provided in academic L1 contexts, and it is worthinvestigating how it is affected by different types of errors, in response to different types of feedback, and by variations in WM capacity. 
A third limitation may be that we examined the overall semantic error-correction in the study, and did not take into consideration the potential differences of semantic error subtypes on error-correction in response to WCF, which was mainly due to lack of evidence on differences between these error subtypes. This may actually be a determining factor in semantic error-correction performance which needs to be dealt with in future studies.

Finally, we attempted to examine the effect of error-correction time as a covariate in our data analysis. Accordingly, we asked the participants to write down the time they spent doing the correction task at the end of the text. The task itself was not timed; however, the presence of a clock on the screen showing the elapsed time may have given the participants the feeling that it was a timed task and they had to finish as quickly as possible. So, we believe it could have exerted a sort of time pressure on participants and in turn to led to such poor performance in correcting semantic errors.

\section{Conclusion}

Our findings suggest that both error types and WM are associated with native French participants' written error-correction (proofreading) performances in response to the WCF they received. Typographical, orthographic, and grammatical error correction, although different in the processing they require to detect and correct them, were not significantly different between direct-metalinguistic and indirect WCF groups. It was the semantic errors that made a difference between the effectiveness of the two WCF types, indicating that directmetalinguistic WCF is more effective in correcting semantic errors. Direct-metalinguistic WCF is more explicit in nature and provides more information regarding the error type, requiring the participants to read the sentences for meaning to perform the correction on semantic errors which require a global processing of the sentence. Indirect WCF has similar effects on the correction of typographical, orthographic, and grammatical errors which demand word-level and local processing respectively, but not on semantic errors since this 
form of feedback may not make this type of error as salient as direct-metalinguistic WCF does. In summary, the presence of WCF, in general, equally facilitated error correction that require word-level and local processing, but it had different effects on the correction of semantic errors that need global processing.

WM as well as its processing component was also found to be associated with directmetalinguistic WCF effectiveness in correcting semantic errors, indicating that participants used more cognitive effort in dealing with this error. This was compared with the indirect WCF, where participants were informed about the location of the error, but the identification of the error type was communicated to them, which was found to be done effortfully for semantic errors, and ultimately resulted in no correction of this error type. Indirect WCF reduced participants' dependency on WM for the correction of semantic errors since the processing was mostly kept at the world level or because the cognitive effort resulting from this form of feedback was so high that participants decided to leave the error uncorrected, which led to a low association between WM and error-correction in this group. Finally, another possible explanation for such a weak association may be a floor effect, where some of the participants in the indirect group scored near zero, thus reducing the variance of scores. We need to bear in mind that this may have attenuated the association between WM and indirect FB effectiveness on self error correction.

\section{References}

Ammar, A. (2008). Prompts and recasts: Differential effects on second language morphosyntax. Language Teaching Research, 12, 183-210.

Ashwell, T. (2000). Patterns of teacher response to student writing in a multiple-draft composition classroom: Is content feedback followed by form feedback the best method? Journal of Second Language Writing, 9, 227-258.

Baddeley, A. D. (2000). The episodic buffer: A new component of working memory? Trends in Cognitive Sciences, 4, 417-423.

Baddeley, A. D. (2003). Working memory: Looking back and looking forward. Nature Reviews Neuroscience, 4, 829-839. 
Baddeley, A. D. (2007). Working memory, thought, and action. Oxford: Oxford University Press.

Baddeley, A. D., \& Hitch, G. J. (1974). Working memory. In S. Dornic (Ed.), Recent advances in learning and motivation (pp. 47-89). New York: Academic Press.

Beal, C., Bonitatibus, G. J., \& Garrod, A. C. (1990). Fostering children's revision skills through training in comprehension monitoring. Journal of Educational Psychology, 82, 275-280.

Bitchener, J. (2008). Evidence in support of written corrective feedback. Journal of Second Language Writing, 17, 102-118.

Bitchener, J. (2009a). Measuring the effectiveness of written corrective feedback: A response to "Overgeneralization from a narrow focus: A response to Bitchener (2008)". Journal of Second Language Writing, 18, 276-279.

Bitchener, J. (2009b). The relative effectiveness of different types of direct written corrective feedback. System, 37, 322-329.

Bitchener, J., \& Ferris, D. R. (2012). Written corrective feedback in second language acquisition and writing. New York: Routledge.

Bitchener, J., \& Knoch, U. (2008). The value of written corrective feedback for migrant and international students. Language Teaching Research, 12, 409-431.

Bitchener, J., \& Knoch, U. (2010a). The contribution of written corrective feedback to language development: A ten-month investigation. Applied Linguistics, 31, 193-214.

Bitchener, J., \& Knoch, U. (2010b). Raising the linguistic accuracy level of advanced L2 writers with written corrective feedback. Journal of Second Language Writing, 19, 207-217.

Bitchener, J., Young, S., \& Cameron, D. (2005). The effective of different types of corrective feedback on ESL student writing. Journal of Second Language Writing, 14, 191-205.

Chandler, J. (2003). The efficacy of various kinds of error feedback for improvement in the accuracy and fluency of L2 student writing. Journal of Second Language Writing, 12, 267-296.

Chromik, M. (2002). Proofreading, Its Value, and Its Place in the Writing Center. Available online: http://eric.ed.gov/?id=ED476401. Retrieved August 19, 2017.

Coben, H. (1998). One false move (P. Benita, Trans.). New York: Delacorte Press.

Conway, A. R. A., Jarrold, C., Kane, M. J., Miyake, A., \& Towse, J. N. (2007). Variation in working memory: An introduction. In A. R. A. Conway, C. Jarrold, M. J. Kane, A. Miyake, \& J. N. Towse (Eds.), Variation in working memory (pp. 3-17). Oxford: Oxford University Press.

Conway, A. R. A., Kane, M. J., Bunting, M. F., Hamrick, D. Z., Wilhelm, O., \& Engle, R. W. (2005). Working memory span tasks: A methodological review and user's guide. Psychonomic Bulletin \& Review, 12, 769-786.

Conway, A. R. A., Kane, M. J., \& Engle, R. W. (2003). Working memory capacity and its relation to general intelligence. Trends in Cognitive Sciences, 7, 547-552.

Cowan, N. (2005). Working memory capacity. New York: Psychology Press.

Daneman, M., \& Carpenter, P. A. (1980). Individual differences in working memory and reading. Journal of Verbal Learning and Verbal Behavior, 19, 450-466.

Daneman, M., \& Stainton, M. (1993). The generation effect in reading and proofreading: Is it easier or harder to detect errors in one's own writing? Reading and Writing: An Interdisciplinary Journal, 5, 297-313.

Ellis, R. (2010). Epilogue: A framework for investigating oral and written corrective feedback. Studies in Second Language Acquisition 32, 335-349.

Ellis, R., Loewen, S., \& Erlam, R. (2006). Implicit and explicit corrective feedback and the acquisition of L2 grammar. Studies in Second Language Acquisition, 28, 339-268.

Ene, E., \& Upton, T. A. (2018). Synchronous and asynchronous teacher electronic feedback and learner uptake in ESL composition. Journal of Second Language Writing, 41, 1-13.

Engle, R. W., Kane, M. J., \& Tuholski, S. W. (1999). Individual differences in working memory capacity and what they tell us about controlled attention, general fluid intelligence and functions of the prefrontal cortex. In A. Miyake \& P. Shah (Eds.), Models of working memory (pp. 102-134). Cambridge: Cambridge University Press.

Evans, W. S., Caplan, D., Ostrowski, A., Michaud, J., Guarino, A. J., \& Waters, G. (2015). Working memory and the revision of syntactic and discourse ambiguities. Canadian Journal of Experimental Psychology, 69, 136-155. 
Ferris, D. R. (1999). The case for grammar correction in L2 writing classes: A response to Truscott (1996). Journal of Second Language Writing, 8, 1-10.

Ferris, D. R. (2006). Does error feedback help student writers? New evidence on the short and longterm effects of written error correction. In K. Hyland \& F. Hyland (Eds.), Feedback in second language writing: Contexts and issues (pp. 81-104). Cambridge: Cambridge University Press.

Ferris, D. R. (2010). Second language writing research and written corrective feedback in SLA: Intersections and practical applications. Studies in Second Language Acquisition, 32, 181201.

Ferris, D. R., Liu, H., Sinha, A., \& Senna, M. (2013). Written corrective feedback for individual L2 writers. Journal of Second Language Writing, 22, 307-329.

Ferris, D. R, \& Roberts, B. J. (2001). Error feedback in L2 writing classes: How explicit does it need to be? Journal of Second Language Writing, 10, 161-184.

Foin, A. \& Lange, E. (2007). Generation 1.5 writers' success in correcting errors marked on an out-ofclass paper. CATESOL Journal, 19, 146-163.

Gathercole, S. E., \& Alloway, T. P. (2008). Working memory and learning: A practical guide. London: Sage.

Goldschneider, J. M., \& DeKeyser, R. M. (2001). Explaining the "natural order of L2 morpheme acquisition in English': A meta-analysis of multiple determinants. Language Learning, 51, $1-50$.

Goldstein, L. (2006). Feedback and revision in second language writing: Helping learners become independent writers. In K. Hyland \& F. Hyland (Eds.), Feedback in second language writing: Contexts and issues (pp. 185-205). Cambridge: Cambridge University Press.

Guénette, D. (2010). La rétroaction corrective à l'écrit: Pratiques et croyances, deux réalités parallèles? Canadian Modern Language Review, 66, 935-966.

Hacker, D. J., Plumb, C., Butterfield, E. C., Quathamer, D., \& Heineken, E. (1994). Text revision: Detection and correction of errors. Journal of Educational Psychology, 86, 65-78.

Hayes, J. R. (1996). A new framework for understanding cognition and affect in writing. In C. M. Levy \& L. S. Ransdell (Eds.), The science of writing: Theories, methods, individual differences and applications (pp. 1-27). Hillsdale, NJ: Erlbaum.

Hayes, J. R., \& Chenoweth, N. A. (2006). Is working memory involved in the transcribing and editing of texts? Written Communication, 23, 135-149.

Jarrold, C., \& Towse, J. N. (2006). Individual differences in working memory. Neuroscience, 139, 3950 .

Juffs, A. (2004). Representation, processing and working memory in a second language. Transactions of the Philological Society, 102, 199-225.

Kellogg, R. T. (1996). A model of working memory in writing. In C. M. Levy \& S. Ransdell (Eds.), The science of writing: Theories, methods, individual differences and applications (pp. 5771). Mahwah, NJ: Lawrence Erlbaum.

Kellogg, R. T., Whiteford, A. P., Turner, C. E., Cahill, M., \& Mertens, A. (2013). Working memory in written composition: An evaluation of the 1996 model. Journal of Writing Research, 5, 159190.

Kormos, J. (2012). The role of individual differences in L2 writing. Journal of Second Language Writing, 21, 390-403.

Lalande, J. F. (1982). Reducing composition errors: An experiment. Modern Language Journal, 66, $140-149$.

Larigauderie, P., Gaonac'h, D., \& Lacroix, N. (1998). Working memory and error detection in texts: What are the roles of the central executive and the phonological loop? Applied Cognitive Psychology, 12, 505-527.

Larigauderie, P., Guignouard, E., \& Olive. T. (2020). Proofreading by students: Implications of executive and non-executive components of working memory in the detection of phonological, orthographical, and grammatical errors. Reading and Writing, 33, 1015-1036.

Leeser, M. J. (2007). Learner-based factors in L2 reading comprehension and processing grammatical form: Topic familiarity and working memory. Language Learning, 57, 229-270. 
Levy, B. A. (1983). Proofreading familiar text: Constraints on visual processing. Memory \& Cognition, 11, 1-12.

Levy, B. A., Di Persio, R., \& Hollingshead, A. (1992). Fluent rereading: Repetition, automaticity, and discrepancy. Journal of Experimental Psychology: Learning, Memory, and Cognition, 18, 957-971.

Li, S., \& Roshan, S. (2019). The associations between working memory and the effects of four different types of written corrective feedback. Journal of Second Language Writing, 45, $1-15$.

Lopez, M. B., Van Steendam, E., \& Buyse, K. (2017). Comprehensive corrective feedback on low and high proficiency writers. International Journal of Applied Linguistics, 168, 91-128.

Lopez, M. B., Van Steendam, E., Speelman, D., \& Buyse, K. (2018). The differential effects of comprehensive feedback forms in the second language writing class. Language Learning, $68,813-850$.

Matthews, P. H. (2007). Concise dictionary of linguistics. New York: Oxford University Press.

McCutchen, D. (2000). Knowledge, processing, and working memory: Implications for a theory of writing. Educational Psychologist, 35, 13-23.

McCutchen, D., Francis, M., \& Kerr, S. (1997). Revising for meaning: Effects of knowledge and strategy. Journal of Educational Psychology, 89, 667-676.

Miyake, A. (2001). Individual differences in working memory: Introduction to the special section. Journal of Experimental Psychology: General, 130, 163-168.

Olive, T. (2004). Working memory in writing: Empirical evidence from the dual-task technique. European Psychologist, 9, 32-42.

Olive, T. (2012). Working memory in writing. In V. Berninger, Past, present, and future contributions of cognitive writing research to cognitive psychology (pp. 485-503). New York: Psychology Press.

Olive, T. (2014). Toward a Parallel and Cascading Model of the Writing System: A Review of Research on Writing Processes Coordination. Journal of Writing Research, 6, 141-171.

Olive, T., Kellogg R. T., \& Piolat, A. (2001). The triple task technique for studying the process of writing. In T. Olive \& C. M. Levy (Eds), Contemporary tools and techniques for studying writing (pp. 31-58). Dordrecht: Kluwer Academic Publishers.

Pawlak, M. (2014). Error correction in the foreign language classroom: Reconsidering the issues. Heidelberg: Springer.

Pilotti, M., Chodrow, M., \& Thornton, K. C. (2004). Error detection in text: Do feedback and familiarity help? The Journal of General Psychology, 131, 242-266.

Pilotti, M., Maxwell, K., \& Chodorow, M. (2006). Does the effect of familiarity on proofreading change with encoding task and time? Journal of General Psychology, 133, 287-299.

Piolat, A., \& Medard, S. (1998). Effects of the reading span and of the spelling level of writers on the revision of spelling problems. Poster at the 1998 European Conference on Writing and learning to write at the dawn of the 21st century, Poitiers, France, July 2-4.

Piolat, A., Roussey, J-Y., Olive, T., \& Amada, M. (2004). Processing time and cognitive effort in revision: Effects of error type and of working memory capacity. In L. Allal., L. Chanquoy., \& P. Largy (Eds.), Revision: Cognitive and instructional processes (pp. 21-38). Dordrecht, The Netherlands: Kluwer Academic Publishers.

Qi, D. S., \& Lapkin, S. (2001). Exploring the role of noticing in a three-stage second language writing task. Journal of Second Language Writing, 10, 277-303.

Robb, T., Ross, S., \& Shortreed, I. (1986). Salience of feedback on error and its effect on EFL writing quality. TESOL Quarterly, 20, 83-93.

Robinson, P. (1995). Attention, memory and the noticing hypothesis. Language Learning, 45, 283331.

Rosen, V. M., \& Engle, R. W. (1998). Working memory capacity and suppression. Journal of Memory and Language, 39, 418-436.

Roussey, J. Y., \& Piolat, A. (2008). Critical reading effort during text revision. European Journal of Cognitive Psychology, 20, 765-792.

Sachs, R., \& Polio, C. (2007). Learners' uses of two types of written feedback on a L2 writing revision task. Studies in Second Language Acquisition, 29, 67-100. 
Semke, H. (1984). The effects of the red pen. Foreign Language Annals, 17, 195-202.

Shafto, M. A. (2015). Proofreading in young and older adults: The effect of error category and comprehension difficulty. International Journal of Environmental Research and Public Health, 12, 14445-14460.

Sheen, Y. (2007). The effect of focused written corrective feedback and language aptitude on ESL learners' acquisition of articles. TESOL Quarterly, 41, 255-283.

Shintani, N., \& Ellis, R. (2013). The comparative effect of direct written corrective feedback and metalinguistic explanation on learners' explicit and implicit knowledge of the English indefinite article. Journal of Second Language Writing, 22, 286-306.

Spada, N., \& Lightbown, P. M. (2010). Second language acquisition. In N. Schmitt (Eds.) An introduction to applied linguistics (pp. 108-123). London: Hodder Education.

Stefanou, C., \& Revesz, A. (2015). Direct written corrective feedback, learner differences, and the acquisition of second language article use for generic and specific plural reference. Modern Language Journal, 99, 263-282.

Storch, N., \& Wigglesworth, G. (2010). Learners' processing, uptake, and retention of corrective feedback on writing. Studies in Second Language Acquisition, 32, 303-334.

Truscott, J. (1996). The case against grammar correction in L2 writing classes. Language Learning, $46,327-369$.

Truscott, J. (2007). The effect of error correction on learners' ability to write accurately. Journal of Second Language Writing, 16, 255-272.

Truscott, J. \& Hsu, A.Y-P. (2008). Error correction, revision, and learning. Journal of Second Language Writing, 17, 292-305.

Turner, M. L., \& Engle, R. W. (1989). Is working memory capacity task dependent? Journal of Memory and Language, 28, 127-154.

Unsworth, N., \& Engle, R. W. (2007). The nature of individual differences in working memory capacity: Active maintenance in primary memory and controlled search from secondary memory. Psychological Review, 114, 104-132.

Unsworth, N., Heitz, R. P., Schrock, J. C., \& Engle, R. W. (2005). An automated version of the operation span task. Behavior Research Methods, 37, 498-505.

Van Beuningen, C., de Jong, N. H., \& Kuiken, F. (2008). The effect of direct and indirect corrective feedback on L2 learners' written accuracy. ITL International Journal of Applied Linguistics, 156, 279-296.

Van Beuningen, C., de Jong, N. H., \& Kuiken, F. (2012). Evidence on the effectiveness of comprehensive error correction in Dutch multilingual classrooms. Language Learning, 62, $1-41$.

Vyatkina, N. (2010). The effectiveness of written corrective feedback in teaching beginning German. Foreign Language Annals 43, 671-689.

Watanabe, Y., \& Swain, M. (2007). Effects of proficiency differences and patterns of pair interaction on second language learning: Collaborative dialogue between adult ESL learners. Language Teaching Research, 11, 121-142.

Waters, G. S., \& Caplan, D. (1996). The measurement of verbal working memory capacity and its relation to reading comprehension. The Quarterly Journal of Experimental Psychology, 49, $51-79$.

White, L. (1991). Adverb placement in second language acquisition: Some positive and negative evidence in the classroom. Second Language Research, 12, 223-265. 


\section{Appendix A}

A Sample of the OSPAN used in the study (set size 2)

- Slide one: $2+(4-2)=$ ? (3000 milliseconds)

- Slide two: 4? Yes? No? $(3000 \mathrm{~ms})$ [Here, students are required to decide if 4 is the correct answer to the question, and mark 'yes' or 'no' on their answer sheet in $3000 \mathrm{~ms}$ ]

- Slide three: B (shown for $1000 \mathrm{~ms}$ ) [This is the recall item. Students need to keep it in their memory until asked to write it on their answer sheet]

- Slide four: $6-(2+2)=$ ? $(3000 \mathrm{~ms})$

- Slide five: 4? Yes? No? (Shown for $3000 \mathrm{~ms}$ )

- Slide six: H (shown for $1000 \mathrm{~ms}$ )

- Slide 7: Rappel [This is the recall cue which means 'recall' or 'remember' in French. Seeing this, students must write the alphabetical letters in the order of presentation (i.e., B/H) on their answer sheet. The time allotted for a set size of 2 is $4000 \mathrm{~ms}$.]

\section{Appendix B}

The text used in the study with errors underlined

Le bus de campagne d'Arthur Bradford arborait évidmement des rayures rouges et lourdes et de grosses étoile blanches. BRADFORD GOUVERNEUR était inscrit sur les flancs en caractères 3-D obliques. Stylisés. Les vitres étaient tintées de façon à ce que le grand dirigeant ne soit pas offert au regard du vulgaire. Chacun a le droit de se sentir chez soi.

Arthur Bradford se tenait près de la croisée du car, micro en main. Frère Chance était juste derrière lui, montrant sa dentitoin au cas où la caméra s'attarderait sur lui. C'était le sourire regardez-comme-notre-candidat-est-génial de celui qui a voccation à servir d'ombre à son suzerain. A sa droite, se trouvais Terence Edwards, le cousin de Brenda. Également affublé d'un sourire aussi naturel qu'une pub pour dentifrice couleur. Tous deux arboraeint des chapaux cotillons que les politiciens en campagne distribuent au bon peuple.

La foule clairsemée était essentiellement composée de vieux. De très vieux. Ils semblaient distrait comme si on les avait attirés ici avec la promesse d'un buffet grautit. D'autres passants ralantissaient pour voir ce qui se mangeait, un peu comme ces gens qui se coagule accident en espérant voir un peu de sang. Les sbires de Bradford se mêlaient au public, distribaunt pancartes, pin's et même quelques-uns de ces couvre-chefs sucrés grotesques, arborant tous le slogan BRADFORD GOUVERNEUR en lettrage conpliqué. De temps à autre, ils interrompaient leur distribution pour se mettre à applaudir et le reste de la foule les imitaient sans conviction. 